\title{
Collagenous colitis: Jejunal and colorectal pathology
}

\author{
J Armes, D C Gee, F A Macrae, W Schroeder, P S Bhathal
}

\begin{abstract}
Aims: To determine: (1) whether there is an association between collagenous colitis and coeliac disease or lymphocytic colitis; (2) the distribution of lymphocyte subsets and macrophages in the lamina propria and surface epithelial layer in collagenous colitis; and (3) the colorectal distribution of the disease and whether a mucosal biopsy specimen, using a flexible sigmoidoscope, is sufficient to diagnose it.

Methods: The clinical data and colorectal biopsy specimens from 38 patients with collagenous colitis were studied. In 10 , small bowel biopsy specimens were also available for review. Immunostaining of the mucosal lymphoid infiltrate with a panel of relevant antibodies was carried out on formalin fixed tissue in seven cases; in three the phenotyping was performed on fresh biopsy specimens separately frozen or fixed in $B 5$ solution.
\end{abstract}

Results: Coeliac disease was found in four out of the 10 patients with collagenous colitis who had had a small bowel biopsy, in contrast to the prevalence of the disease in Australia of 1 in 3000. Collagenous colitis did not respond to gluten withdrawal. Five of $29(17 \%)$ of the patients had a mixed pattern of lymphocytic and collagenous colitis. Immunostaining of the lymphoid infiltrate showed that the striking increase in intraepithelial lymphocytes in collagenous colitis was due to an influx of $\mathrm{CD8}$ positive cells. The occurrence and severity of collagenous colitis along the large bowel were independent of the anatomical site, and in more than $90 \%$ of cases biopsy specimens from the sigmoid colon or rectum were diagnostic.

Conclusions: There is a very high incidence of coeliac disease among patients with collagenous colitis so that jejunal biopsy should be an essential part of their investigations, especially if symptoms persist. However, only a minority showed a mixed pattern of lymphocytic and collagenous colitis. The intraepithelial lymphocytes in collagenous colitis are CD8 positive cells. Collagenous colitis can be diagnosed from rectal or sigmoid colon biopsy specimens in more than $90 \%$ of cases.

Collagenous colitis is characterised by chronic watery diarrhoea, minimal or absent endoscopic findings, and the presence of microscopic mucosal inflammation, together with thickening of the subepithelial collagen plate. $^{1}$

Sporadic cases of collagenous colitis in patients with coeliac disease have been reported $^{2-5}$ and a similar aetiology for coeliac disease and collagenous colitis has been proposed. ${ }^{67}$ However, in two recent studies of patients with coeliac disease no association with collagenous colitis was found, although lymphocytic colitis was detected in some of the patients. ${ }^{89}$ Lymphocytic colitis is similar clinically to collagenous colitis, but differs microscopically in the absence of a thickened collagen plate. ${ }^{67}$

The association between collagenous colitis and both coeliac disease and lymphocytic colitis was investigated in a histopathological and limited immunohistological study of 38 patients with collagenous colitis. We also determined the anatomical distribution of collagenous colitis within the large bowel, because awareness of its distribution should help localise the site for a diagnostic endoscopic biopsy.

\section{Methods}

Large bowel biopsy specimens from 38 patients with collagenous colitis taken between 1986 and 1991 were reviewed from the files of The Royal Melbourne Hospital and a large private pathology practice. All patients had chronic watery diarrhoea and met the histological criteria of collagenous colitis comprising band-like thickening of the collagen plate ( $\geqslant 10 \mu \mathrm{m})$, an increase in surface intraepithelial lymphocytes, surface epithelial damage with loss of mucin production and cellular cuboidalisation, and a mixed inflammatory cell infiltrate in the lamina propria and normal crypt architecture. ${ }^{6710}$ The biopsy specimens had been routinely fixed in formalin, embedded in paraffin wax, and stained with haematoxylin and eosin and Masson's trichrome or the picro-Mallory stain. In each case the thickness of the collagen plate was measured with a graticule.

Duodenal or jejunal biopsy specimens were also available from 10 of the 38 patients. Data regarding the anatomical site of multiple large bowel biopsy specimens were available in 19 of the 38 cases; 12 had specimens taken from the left and right colon and the rectum, and seven had them taken from the left and right colon, but not the rectum. Nineteen of the 38 patients had specimens taken from either the rectum or the sigmoid colon. Twenty nine of the 38
Correspondence to: Professor P S Bhathal

Accepted for publication 24 February 1992 
patients had multiple synchronous large bowel biopsy specimens taken, allowing the histological features within one patient to be compared.

Immunostaining of the mucosal lymphoid infiltrate in formalin fixed, paraffin wax embedded tissue was carried out in seven cases using a panel of antibodies (table) and the peroxidase anti-peroxidase technique. In an additional three patients fresh biopsy specimens were separately frozen or fixed with $10 \%$ formalin or B5 solution. Lymphocyte subset distribution in cryostat sections was determined by using additional antibodies (table). Non-inflamed colorectal mucosal biopsy specimens were available from four patients undergoing colonoscopy for diarrhoea, who were subsequently found to have the irritable bowel syndrome. These were used as control specimens in the immunohistological analysis.

\section{Results}

Of the 38 patients with collagenous colitis in the study, $27(71 \%)$ were female and 11 $(29 \%)$ were male, giving a gender ratio of $2 \cdot 45: 1$. The age range for males was $50-86$ years, with a mean (SD) of 67.8 (9.92) years; the age range for females was $25-83$ years, with a mean (SD) of $65.0(16.3)$ years.

ASSOCIATION BETWEEN COLLAGENOUS COLITIS AND COELIAC DISEASE

Four of the 10 patients from whom duodenal and jejunal biopsy specimens were available had microscopic features consistent with coeliac disease. In two the diagnosis of coeliac disease preceded that of collagenous colitis and both were already excluding gluten from their diet. Of the four patients with coeliac disease, two had broad collagen bands within the lamina propria, an appearance consistent with collagenous sprue. Two of the four patients (including one with collagenous sprue) had a small bowel biopsy repeated after adherence to a gluten free diet and both showed reversal of their small bowel pathology. However, the collagenous colitis did not respond to a gluten free diet. The remaining six patients within this subset had normal upper small bowel histology.

LYMPHOCYTE SUBSET DISTRIBUTION

Compared with the control colorectal tissue, immunohistological analysis of large bowel biopsy specimens from seven patients with collagenous colitis showed that the increase of intraepithelial lymphocytes was caused by higher numbers of $\mathrm{T}$ lymphocytes. Further- more, in three of these cases, immunostaining for lymphocyte subsets on frozen sections showed that the intraepithelial lymphocytes were CD8 positive. In contrast, the lamina propria contained more CD4 positive lymphocytes than CD8 positive lymphocytes (fig 1). Both B lymphocytes and macrophages were present throughout the lamina propria, but macrophages were more numerous within the superficial lamina propria, in close proximity to the surface epithelium.

\section{ASSOCIATION BETWEEN LYMPHOCYTIC AND}

COLLAGENOUS COLITIS

To determine whether multiple biopsy specimens taken from different sites from the same patient would show a combination of both lymphocytic and collagenous colitis (mixed pattern of disease) or whether only collagenous colitis would be present, 29 of the 38 cases were studied because biopsy specimens from multiple sites were available for them. Only five of the $29(17 \%)$ patients had both collagenous colitis and lymphocytic colitis when the specimens were taken from different sites synchronously (fig 2). In four of the five patients with mixed colonic disease the thickened collagen plate was present in the distal large bowel, but the proximal colon showed features of lymphocytic colitis. Interestingly, in contrast to the female predominance of the study group as a whole, four of the five patients with the mixed pattern of colonic disease were male.

\section{ANATOMICAL DISTRIBUTION OF COLLAGENOUS} COLITIS

In 19 of the 38 patients multiple biopsy specimens taken from different named sites within the large bowel were available. In 12 of these patients it was possible to assess whether the right or left colon or rectum were more severely affected (determined by the thickness of the collagen plate), and in a further seven patients the severity of the disease between the left and right colon could be compared. No significant difference emerged. Of the 19 patients who had biopsy specimens taken from either the rectum or sigmoid colon, 18 showed that a biopsy specimen from one of these two sites was diagnostic for collagenous colitis.

\section{Discussion}

Collagenous colitis causes chronic watery diarrhoea that is associated with well defined histopathological changes in the large bowel mucosa. However, there are uncertainties regarding its pathogenesis, its association with

Panel of antibodies used in immunohistological study

\begin{tabular}{|c|c|c|c|}
\hline \multicolumn{2}{|c|}{ Formalin or B5-fixed, paraffin wax embedded } & \multicolumn{2}{|c|}{ Fresh frozen tissue, cryostat sections } \\
\hline Antibody (source) & Molecule/cell detected & Antibody (source) & Molecule/cell detected \\
\hline $\begin{array}{l}\text { L26 (Dako) } \\
\text { 4KB5 (Dako) } \\
\text { Leu22 (B-D } \\
\text { UCHL1 (Dako) } \\
\text { Mac387 (Dako) }\end{array}$ & $\begin{array}{l}\text { B cell } \\
\text { B cell } \\
\text { T cell } \\
\text { T cell } \\
\text { Macrophage, monocyte, } \\
\text { granulocyte }\end{array}$ & $\begin{array}{l}\text { B1 (Coulter) } \\
\text { B2 (Coulter) } \\
\text { Leu4 (B-D) } \\
\text { Leu3/3a (B-D) } \\
\text { OKT8 (Ortho) } \\
\text { LeuM5 (B-D) }\end{array}$ & $\begin{array}{l}\text { B-cell } \\
\text { B-cell } \\
\text { CD3/T-cell } \\
\text { CD4/T } \\
\text { CD8/1-cell } \\
\text { Macrophage, monocyte } \\
\text { Macell }\end{array}$ \\
\hline
\end{tabular}

${ }^{\star}$ B-D Becton Dickinson 

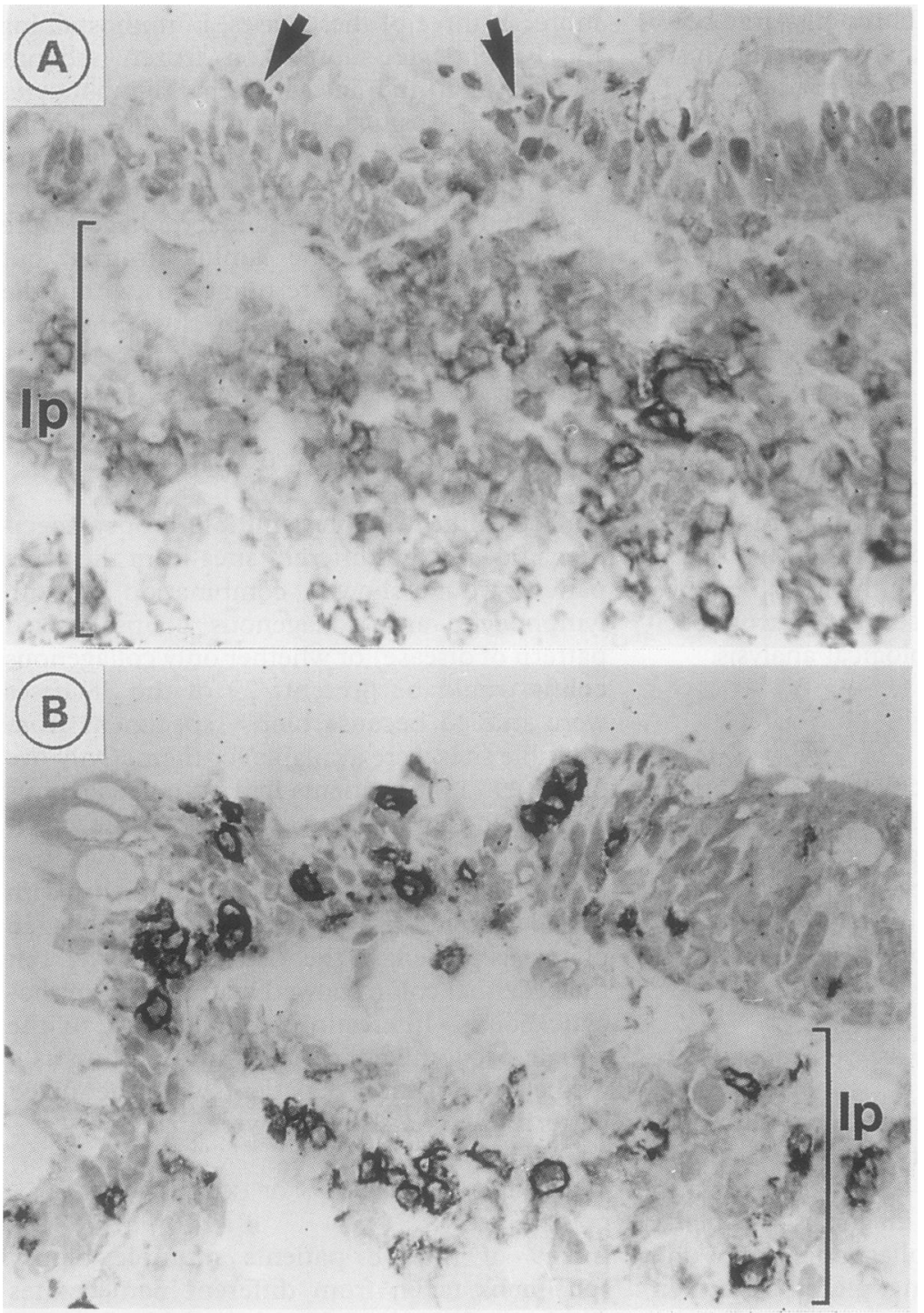

Figure 1 Frozen sections of large bowel mucosa in collagenous colitis immunostained by the peroxidase-antiperoxidase method. (A) The infiltrate in the lamina propria ( $(\mathrm{p})$ is of $C D 4+T$ cells. The lymphocytes in the surface epithelium are CD4-(arrows). (B) In contrast, $C D 8+T$ cells populate both the lamina propria and epithelium.

both coeliac disease and lymphocytic colitis, and the anatomical distribution of the disease within the large bowel.

Of the 10 patients from whom small bowel biopsy specimens were available, four showed microscopic features consistent with coeliac disease, indicating a significant association in view of the prevalence of coeliac disease in the Australian population of 1 in $3000 .^{11}$ Thus this study complements earlier case reports which indicate that patients with coeliac disease may also develop collagenous colitis ${ }^{2-5}$ and differs from the studies by Du Bois et al and Wolber et al which did not detect collagenous colitis in patients with coeliac disease, but rather found lymphocytic colitis in some of them. ${ }^{89}$ Interestingly, two of our four cases also had an increase of collagen within the small bowel lamina propria, consistent with collagenous sprue, an association that has been noted before by other workers. ${ }^{1213}$ Our findings suggest that jejunal biopsy should be an essential part of the investigative workup of patients with collagenous colitis, especially if symptoms persist.

The pathogenesis of collagenous colitis remains undetermined. Attention has been drawn to similarities between the pathogenesis of collagenous colitis and coeliac disease. ${ }^{6}$ Coeliac disease is thought to be an immunopathological disease caused by sensitivity to the wheat protein gluten, perhaps triggered by adenovirus type 12 infection in certain susceptible individuals. ${ }^{14}$ In our four patients with coeliac disease collagenous colitis persisted despite a gluten free diet. Indeed, in two of these patients the discovery of collagenous colitis followed the diagnosis of coeliac disease and the start of a gluten free diet. The resistance of collagenous colitis to a gluten free diet has been reported before. ${ }^{245}$ Thus it would seem that collagenous colitis is not the result of sensitivity to gluten present within the large bowel. However, as the increased number of intraepithelial lymphocytes is a striking feature of both coeliac disease and collagenous colitis, it is still possible that, in collagenous colitis, sensitivity to a luminal agent other than gluten may stimulate an immunopathological response.

Immunostaining of the biopsy specimens in a proportion of our patients with collagenous colitis showed that, as in coeliac disease, the intraepithelial lymphocytes were of $\mathrm{T}$ cell origin. Furthermore, lymphocyte subset typing in three cases showed that the intraepithelial lymphocytes were CD8 positive, while most lymphocytes within the lamina propria were of CD4 subtype. This finding is similar to that seen in coeliac disease, where an increase of intraepithelial CD8 positive lymphocytes has been described. ${ }^{15}$

The distribution of lymphocyte subsets within the inflamed large bowel mucosa of patients with collagenous colitis sheds additional light on the pathogenesis of the disease. CD8 positive $T$ cells show MHC class I restriction, and in this context the antigen presented is usually a processed peptide of an endogenous antigen selectively bound to class I molecules, unlike antigen presented in association with MHC class II to CD4 positive lymphocytes, which is processed exogenous antigen. ${ }^{16-18}$ In collagenous colitis, therefore, CD8 positive intraepithelial lymphocytes may be stimulated to react by a luminal agent which leads to immuno-crossreactivity with an endogenous antigen produced by the surface enterocytes.

Collagenous colitis shows clinical and microscopic features similar to those of lymphocytic colitis. Indeed, the histological features differ only in terms of collagen plate thickening. It has therefore been suggested that lymphocytic colitis is an earlier stage of collagenous colitis, before the onset of collagen deposition, ${ }^{719}$ or that collagen deposition may be absent or borderline from certain parts of the large bowel, particularly the distal colon and rectum. ${ }^{1020}$ Some clinical aspects of the two diseases, however, indicate that they are separate entities: the equal gender ratio present in lymphocytic colitis, as opposed to the female excess in collagenous colitis; and the differing HLA predominance between the two diseases-namely, HLA-A1 and HLA-DRW53 in 

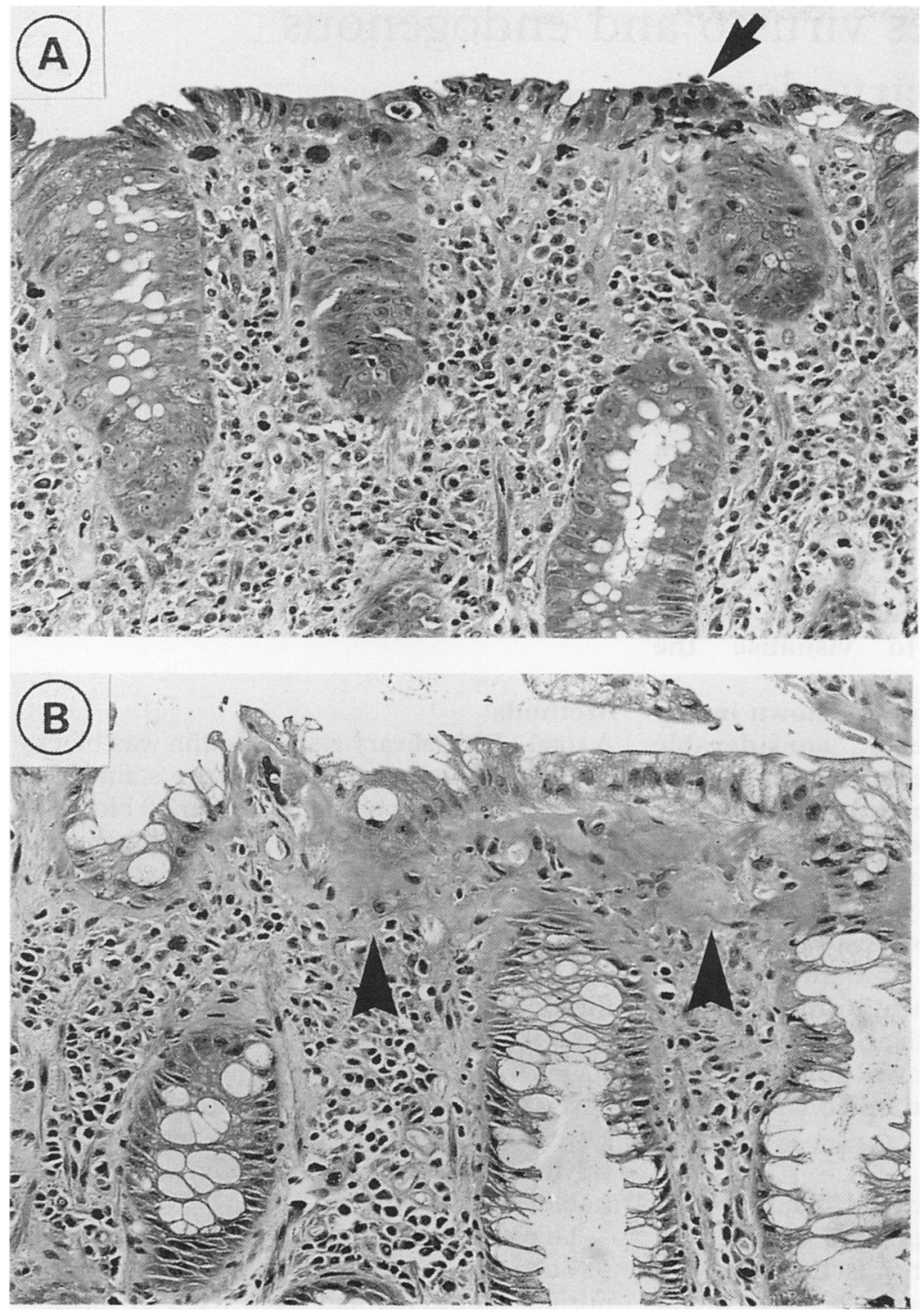

Figure 2 Biopsy specimens taken simultaneously from the caecum and sigmoid colon in one patient showing: (A) features of lymphocytic colitis in the caecum comprising a collagen table of normal thickness and intraepithelial lymphocytic infiltration (arrows); but (B) features of collagenous colitis in the sigmoid colon with band-like thickening of the collagen plate (arrowheads) (Masson trichrome.)

lymphocytic colitis-but no distinct HLA linkage in collagenous colitis. ${ }^{21} \mathrm{~A}$ mixed pattern of lymphocytic and collagenous colitis was found in five of the 29 patients in whom multiple large bowel biopsy specimens were taken at the same time. In these patients with mixed colonic disease absence of a thickened collagen plate did not seem to depend on the site of the biopsy. In each case multiple biopsy specimens were only taken on one occasion and therefore the possibility of subsequent development of complete collagenous colitis could not be assessed. Unlike the female preponderance seen in the main study group ( $71 \%$ compared with $29 \%$ ) and previously reported in patients with collagenous colitis, ${ }^{6}$ four of the five patients with the mixed colonic disease in this study were male. Hence these findings would add support to the hypothesis that collagenous colitis and lymphocytic colitis are separate diseases with similar, but not identical, histological appearances.

Because macroscopic evidence of collagenous colitis is not seen during endoscopic examination, it is important to establish the distribution of disease within the large bowel to determine the site most likely to yield a diagnostic biopsy specimen. It has been reported that in collagenous colitis the collagen plate is thicker in the proximal colon compared with the sigmoid colon and rectum, ${ }^{10}$ and Giardiello et al found that the thickened collagen plate may be absent in the rectum. ${ }^{20}$ However, our study confirms that of Lazenby et al, who found that there was little difference between the degree of collagen thickening in proximal and distal large bowel in patients with collagenous colitis. ${ }^{6}$ Hence, on the basis of the present study, it seems that biopsy specimens taken with a flexible sigmoidoscope are sufficient to diagnose collagenous colitis in over $90 \%$ of cases.

This study was presented in part at the 36th Annual Scientific Meeting of The Royal College of Pathologists of Australasia, Melbourne, 30 September-4 October 1991.

We thank Mr F Fellepa and Ms L Turnham for their excellent laboratory assistance and Ms T Dentry for typing the manuscript. We also thank the many gastroenterologists and surgeons who allowed us to study their patients' biopsy specimens.

1 Lindstrom CG. "Collagenous colitis" with watery diarrhoea. A new entity? Pathol Eur 1976;11:87-9.

2 Hamilton I, Sanders S, Hopwood D, Bouchier IAD. Collagenous colitis associated with small intestinal villous atrophy. Gut 1986;27:1394-8.

3 Breen EG, Coughlan G, Connolly CE, Stevens FM McCarthy CF. Coeliac proctitis. Scand $\mathcal{f}$ Gastroenterol 1987;22:471-7.

4 Cadiot G, Flourie B, Galian A, Lavergne A, Modigliani R. Coeliac disease and collagenous colitis. A fortuitous association. Presse Med 1990;19:1621-2.

5 O'Mahony S, Nawroz IM, Ferguson A. Coeliac disease and collagenous colitis. Postgrad Med $\mathcal{f}$ 1990;66:238-41.

6 Lazenby AJ, Yardley JH, Giardiello FM, Jessurun J, Bayless TM. Lymphocytic ("microscopic") colitis: A comparative histopathologic study with particular reference to collagenous colitis. Hum Pathol 1989;20:18-28.

7 Yardley JH, Lazenby AJ, Giardiello FM, Bayless TM. Collagenous, "microscopic", lymphocytic, and other gentler and more subtle forms of colitis. Hum Pathol gentler and more

8 DuBois RN, Lazenby AJ, Yardley JH, Hendrix TR, Bayless TM, Giardiello FM. Lymphocytic enterocolitis in

9 Wolber R, Owen D, Freeman H. Colonic lymphocytosis in patients with coeliac sprue. Hum Pathol 1990;21: 1092-6.

10 Jessurun J, Yardley JH, Giardiello FM, Hamilton SR, Bayless TM. Chronic colitis with thickening of the subepithelial collagen layer (collagenous colitis): Histopathologic findings in 15 patients. Hum Pathol 1987; 18:839-48.

11 Porter NJ, Duggan JM. Epidemiology of coeliac disease in an Australian community [abstract]. Aust $N Z \mathcal{F} M e d$ 1990; 20:363.

12 Eckstein RP, Dowsett JF, Riley JW. Collagenous enterocolitis: A case of collagenous colitis with involvement of colitis: A case of collagenous colitis with involvement of

13 Stolte M, Ritter M, Borchard F, Koch-Scherrer G. Collagenous gastroduodenitis on collagenous colitis. Endoscopy 1990;22:186-7.

14 Kagnoff MF, Paterson YJ, Kumar PJ, et al. Evidence for the role of a human intestinal adenovirus in the pathogenesis of coeliac disease. Gut 1987;28:995-1001.

15 Selby WS, Janossy G, Bofill M, Jewell DP. Lymphocyte subpopulations in the human small intestine. The findings in normal mucosa and in the mucosa of patients with adult coeliac disease. Clin Exp Immunol 1983;52: 219-28.

16 Germain RN. The ins and outs of antigen processing and presentation. Nature 1986;322:687-9.

17 Townsend A, Bodmer $\mathrm{H}$. Antigen recognition by class restricted T lymphocytes. Ann Rev Immunol 1989; 7:601-24

18 Guagliardi LE, Koppelman B, Blum JS, Marks MS, Cresswell P, Brodsky FM. Co-localization of molecules involved in antigen processing and presentation in an early endocytic compartment. Nature 1990;343:133-9.

19 Sylwestrowicz T, Kelly JK, Hwang WS, Shaffer EA. Collagenous colitis and microscopic colitis: The watery diarrhoea-colitis syndrome. Am $\mathcal{F}$ Gastroenterol 1989;84: 763-8.

20 Giardiello FM, Bayless TM, Jessurun J, Hamilton SR, Yardley JH. Collagenous colitis: Physiologic and histopathologic studies in seven patients. Ann Intern Med 1987;106:46-9.

21 Giardiello FM, Lazenby AJ, Bayless TM, et al. Lymphocytic (microscopic) colitis. Clinicopathologic study of 18 patients and comparison to collagenous colitis. Dig Dis Sci 1989;34:1730-8. 